\title{
Venous thromboembolism: A Call for risk assessment in all hospitalised patients
}

\author{
ISTH Steering Committee for World Thrombosis Day*
}

Thrombosis is a major contributor to the global burden of disease because it is the pathology underlying venous thromboembolism (VTE), ischaemic heart disease, and ischaemic stroke (1). Collectively, these disorders account for about 1 in 4 deaths worldwide (1). Prevention and treatment of thrombosis are critical for reducing global death and disability.

In 2014, the International Society on Thrombosis and Haemostasis (ISTH) declared October 13 as World Thrombosis Day to increase global awareness about thrombosis, including its risk factors and strategies for prevention, diagnosis, and treatment. VTE was selected as the initial focus of World Thrombosis Day because well-established public awareness campaigns were already focusing on heart disease and stroke through World Heart and World Stroke Days. More specifically, hospital-associated VTE was chosen as the focus for increased awareness and action.

This decision was supported by several pieces of evidence. First, there are compelling data from Europe and the United States documenting the burden of VTE, which includes deep-vein thrombosis (DVT) and pulmonary embolism (PE). Cohen et al. estimated that in 2004 there were more than 600,000 DVT events, 400,000 PE events, and 500,000 VTE-related deaths, across the European Union

* See Appendix for Steering Committee members.

Correspondence to:
Gary E. Raskob
College of Public Health
University of Oklahoma Health Sciences Center
801 NE 13th Street
Oklahoma City, OK, 73104, USA
Tel.: + 1405271 2232, Fax: + 14052713039
E-mail: gary-raskob@ouhsc.edu

Received: September 26, 2016

Accepted: September 27, 2016

Epub ahead of print: October 13, 2016

http://dx.doi.org/10.1160/TH16-09-0732

Thromb Haemost 2016; 116: 777-779
(2). In the United States, investigators from the Centers for Disease Control and Prevention estimated that there were more than 500,000 adult hospitalisations with a diagnosis of VTE each year from 2007 to 2009 (3). VTE is responsible for more deaths each year than breast cancer, HIV disease, and motor vehicle crashes combined (2).

Second, the available epidemiologic data indicate that approximately $60 \%$ of cases of VTE are associated with a recent hospital stay (4). The World Health Organisation (WHO) patient safety program found that hospital-associated VTE was a leading cause of death and disability associated with hospitalisation in low, middle, and high income countries and accounted for more deaths and greater disability than nosocomial pneumonia, catheter-related bloodstream infections, and adverse drug events (5).

Public awareness about VTE is low, and lags behind that of other common disorders (6). In a global survey, only $44 \%$ and $54 \%$ of respondents were aware of DVT and $\mathrm{PE}$, respectively, and only $45 \%$ of respondents were aware that most cases of VTE were preventable (6). Even fewer identified hospitalisation as a risk factor (6). An important educational goal of World Thrombosis Day is to arm patients and their families with information to be their own advocates for VTE prevention in high risk settings, such as hospitalisation.

\section{Underuse of methods of proven efficacy for VTE prevention}

Despite the availability of effective methods for thromboprophylaxis, such as anticoagulant drugs or mechanical devices (7-11), global audits have shown underuse in hospitalised patients at risk. In the ENDORSE study (12), conducted in 358 hospitals across 32 countries, only $58.5 \%$ and $30.5 \%$ of at risk surgical and medical patients, respectively, received the appropriate thromboprophylaxis recommended by evidence-based guidelines (12). In hospitalised medical patients, appropriate thromboprophylaxis was used in $70 \%$ or more of patients in only one country and was used in less than $50 \%$ of patients in 23 countries. For surgical patients, the recommended thromboprophylaxis was used in less than $50 \%$ of patients in 13 countries, between $51 \%$ and $75 \%$ in 13 countries, and in over $75 \%$ of patients in six countries (12). Therefore, there is systemic underuse of appropriate thromboprophylaxis.

Why is thromboprophylaxis underused? Although there are multiple contributing factors, key among these is the concern about the risk of bleeding with anticoagulant prophylaxis. Clinicians are reluctant to apply the results from clinical trials that were conducted in carefully selected patients to their patients in whom the risk of bleeding is perceived to be higher or the risk of VTE is considered to be lower than that reported in the trials. With this as the argument against universal thromboprophylaxis, extensive research has focused on the development of risk assessment models to identify hospitalised patients whose risk of VTE is sufficiently high to offset the risk of bleeding with anticoagulant thromboprophylaxis. Several such models have been developed (13-16), and some have undergone extensive independent validation (16-21). There also is evidence that elevated plasma levels of D-dimer, a marker of fibrin degradation, may be useful for identifying medically ill patients at increased risk for VTE (22). Current evidence-based guidelines for VTE prevention now recommend the use of risk assessment to personalise the approach to thromboprophylaxis $(8,9)$.

Experience from the National Health Service in England supports the concept that routine VTE risk assessment in hospitalised patients reduces death and morbidity from VTE. 


\section{Systematic VTE risk assessment: Experience from the United Kingdom}

In 2010, the Department of Health in England introduced a national target for hospitals within the National Health Service (NHS) with the goal of increasing the number of patients assessed for their risk of VTE (23). The program imposed financial penalties for hospitals that failed to perform VTE risk assessment using a standardised risk assessment tool in at least $90 \%$ of patients. The data from evaluations of this initiative have recently become available.

In an observational cohort study that included all patients admitted to NHS hospitals in England between July 2010 and March 2012 (24), Lester et al. tracked VTErelated mortality within 90 days of hospital discharge, and related this mortality to the level of VTE risk assessment at admission. There was a statistically significant reduction in deaths due to VTE in hospitals that reached the targeted level of VTE risk assessment of $90 \%$ or more compared with that in hospitals that fell short of this target (relative risk, 0.85 ; $95 \%$ confidence interval, 0.75 to $0.96)(24)$. The difference was observed in both surgical and non-surgical patients.
Additional data support the value of VTE risk assessment at the time of hospital admission. In a retrospective population-based study (25), Catterick and Hunt determined the rates of VTE mortality and VTE-related readmission at 30 and 90 days in 2011 and 2012 and compared these rates with those expected based on linear regression analysis of the trends observed from 2006-2007 to 2011-2012. The annual national rates of VTE-related mortality for 2011 and 2012 were $91 \%$ and $92 \%$, respectively, of the estimated rates and these rates were also lower than the rates observed between 2007 and 2010 (25). In addition, readmission rates related to VTE at 30 and 90 days were $4 \%$ lower than the estimated rates in both 2011 and 2012. Although this study has limitations, such a prompt effect on VTE-related death and readmission observed in the first and second year after implementation of routine VTE risk assessment suggests that this strategy reduces fatal and non-fatal hospital-associated VTE. The authors estimated that more than 900 VTE-related deaths were avoided in England during 2011 and 2012 by this strategy (25). Similar data on the reduction of hospital- associated VTE by implementing routine risk assessment are emerging from other countries (26).

\section{Members of the ISTH Steering Committee for World Thrombosis Day}

G. E. Raskob (Chair) ${ }^{1}$; P. Angchaisuksiri²; A. N. Blanco ${ }^{3} ;$ H. Buller4; H. Ddungu ${ }^{5}$; B. J. Hunt ${ }^{6}$; E. M. Hylek7; A. Kakkar8; S. V. Konstantinides $^{9,10}$; M. McCumber ${ }^{1}$; C. McLintock ${ }^{11} ;$ T. Urano $^{12} ;$ A. Wendelboe ${ }^{1}$; J. I. Weitz ${ }^{13}$

${ }^{1}$ College of Public Health, University of Oklahoma Health Sciences Center, Oklahoma City, Oklahoma, USA; ${ }^{2}$ Faculty of Medicine, Ramathibodi Hospital, Mahidol University, Bangkok, Thailand; ${ }^{3}$ División Hemostasia, IIHEMA, Academia Nacional de Medicina, Buenos Aires, Argentina; ${ }^{4}$ Academic Medical Center, Department of Vascular Medicine, Amsterdam, the Netherlands; ${ }^{5}$ Uganda Cancer Institute, Kampala, Uganda; ${ }^{6}$ Thrombosis \& Thrombophilia Centre, Guy's \& St
Thomas' NHS Foundation Trust, London, UK; ${ }^{7}$ Boston University School of Medicine, Boston, Massachusetts, USA; ${ }^{8}$ Thrombosis Research Institute at University College, London, UK; ${ }^{9}$ Center for Thrombosis and Hemostasis, University Medical Center of the Johannes Gutenberg University, Mainz, Germany; ${ }^{10}$ Department of Cardiology, Democritus University of Thrace, Alexandroupolis, Greece; ${ }^{11}$ National Women's Health, Auckland City Hospital, Auckland, New Zealand; ${ }^{12}$ Department of Medical Physiology, Hamamatsu University School of Medicine, Hamamatsu, Japan; ${ }^{13}$ McMaster University and the Thrombosis and Atherosclerosis Research Institute, Hamilton, Ontario, Canada.

\section{Call to action: VTE risk assessment for all hospitalised patients}

We urge clinical leaders, hospitals and payers to work together to make VTE risk assessment a priority. The evidence is building that the use of VTE risk assessment saves lives and reduces the burden of VTE. We believe that hospitals and hospital systems should incorporate routine risk assessment for all hospitalised patients. The impact of such a policy should continue to be evaluated through best practices of outcomes research and continuous quality improvement. Government and private insurance payers should include VTE risk assessment as part of their payment programs to hospitals. This should include demonstration projects for evaluating different payment models and determining the cost-effectiveness of alternate strategies for VTE risk assessment and prevention. Although the current evidence is not perfect, and no doubt will be updated, the perfect must not be the enemy of the good. We believe that the current evidence is sufficient to take steps now and that by using currently available risk assessment tools, we can reduce death and disability from VTE.

Based on the available evidence, it would be reasonable to use the NHS England risk assessment tool, or alternately, the Caprini risk assessment model for non-orthopedic surgical patients $(13,14,20)$ and the IMPROVE model for hospitalised medical patients $(15,16,18,19)$. VTE risk assessment is not indicated in individual patients undergoing major orthopaedic surgery, such as hip or knee replacement or surgery for hip fracture, because all such patients should receive thromboprophylaxis unless contraindicated. Recent data indicate that measurement of $\mathrm{D}$-dimer is useful as a marker of VTE risk in hospitalised medical patients (22). In the APEX trial (27), medical patients with a D-dimer level more than two times the upper limit of normal appeared to derive the greatest benefit from extended thromboprophylaxis (27). The ongoing MARINER trial is using the IMPROVE risk assessment model together with the $\mathrm{D}$-dimer level to identify 
patients who are randomised to a 45-day course of rivaroxaban or placebo after hospital discharge (28). The combined results of the APEX and MARINER trials will better define which medical patients benefit from extended thromboprophylaxis.

Now is the time to assess the risk of VTE in all hospitalised patients and to use this information to guide the provision of appropriate thromboprophylaxis. Such an approach will likely save lives and reduce morbidity from non-fatal VTE, and has the potential to reduce the incremental costs of VTE to healthcare systems (29).

\section{Conflicts of interest}

Disclosures are on file with the corresponding author.

\section{References}

1. ISTH Steering Committee for World Thrombosis Day. Thrombosis: a major contributor to the global disease burden. Thromb Haemost 2014; 112: 843-852.

2. Cohen AT, Agnelli G, Anderson FA, et al.; VTE Impact Assessment Group in Europe (VITAE). Venous thromboembolism (VTE) in Europe. The number of VTE events and associated morbidity and mortality. Thromb Haemost 2007; 98: 756-764.

3. Yusuf HR, Tsai J, Atrash HK, et al. Venous thromboembolism in adult hospitalisations - United States, 2007-2009. MMWR Morb Mortal Wkly Rep 2012; 61: 401-404.

4. Heit JA. The epidemiology of venous thromboembolism in the community. Arterioscler Thromb Vasc Biol 2008; 28: 370-372.

5. Jha AK, Larizgoitia I, Audera-Lopez C, et al. The global burden of unsafe medical care: analytic modelling of observational studies. BMJ Qual Saf 2013; 22: 809-815.

6. Wendelboe AM, McCumber M, Hylek EM, et al., for the ISTH Steering Committee for World Thrombosis Day. Global public awareness of venous thromboembolism. J Thromb Haemost 2015; 13: $1365-1371$.

7. Qasseem A, Chou R, Humphrey LL, et al., for the Clinical Guidelines Committee of the American College of Physicians. Venous thromboembolism prophylaxis in hospitalised patients: a clinical practice guideline from the American College of Physicians. Ann Intern Med 2011; 155: 625-632.

8. Kahn S, Lim W, Dunn AS, et al.; American College of Chest Physicians. Prevention of VTE in nonsurgical patients: Antithrombotic Therapy and Prevention of Thrombosis, 9th ed: American College of Chest Physicians Evidence-based Clinical Practice Guidelines. Chest 2012; 141 (2 Suppl): e195S-226S.

9. Gould MK, Garcia DA, Wren SM, et al.; American College of Chest Physicians. Prevention of VTE in nonorthopedic surgical patients: Antithrombotic Therapy and Prevention of Thrombosis, 9th ed: American College of Chest Physicians Evidencebased Clinical Practice Guidelines. Chest 2012; 141 (2 Suppl): e227S-277S.

10. Falck-Yitter Y, Francis CW, Johanson NA, et al.; American College of Chest Physicians. Prevention of VTE in orthopedic surgery patients: Antithrombotic Therapy and Prevention of Thrombosis, 9th ed: American College of Chest Physicians Evidence-based Clinical Practice Guidelines. Chest 2012; 141 (2 Suppl): e278S-325S.

11. Nicolaides AN, Fareed J, Kakkar AK, et al. Prevention and treatment of venous thromboembolism international consensus statement. Int Angiol 2013; 32: 111-260.

12. Cohen AT, Tapson VF, Bergmann JF, et al.; ENDORSE Investigators. Venous thromboembolism risk and prophylaxis in the acute hospital care setting (ENDORSE study): a multinational cross-sectional study. Lancet 2008; 371: 387-94. Erratum in: Lancet 2008; 371: 1914.

13. Caprini JA. Thrombosis risk assessment as a guide to quality patient care. Dis Mon 2005; 51: 70-78.

14. Bahl V, Hu HM, Henke PK, et al. A validation study of a retrospective venous thromboembolism risk scoring method. Ann Surg 2010; 251: 344-350.

15. Spyropoulos AC, Anderson FA, Fitzgerald G, et al. Predictive and associative models to identify hospitalised medical patients at risk for VTE. Chest 2011; 140: 706-714.

16. Spyropoulos AC, McGinn T, Khorana A. The use of weighted and scored risk assessment models for venous thromboembolism. Thromb Hamost 2012; 108: 1072-1076.

17. Huang W, Anderson FA, Spencer FA, et al. Riskassessment models for predicting venous thromboembolism among hospitalised non-surgical patients: a systematic review. J Thromb Thrrombolysis 2013; 35: 67-80

18. Mahan CE, Liu Y, Turpie AG, et al. External validation of a risk assessment model for venous thromboembolism in the hospitalised acutely-ill medical patient (VTE-VALOURR). Thromb Hamost 2014; 112: 692-699.

19. Rosenberg D, Eichorn A, Alarcon M, et al. External validation of the risk assessment model of the International Medical Prevention Registry on Venous Thromboembolism (IMPROVE) for medical patients in a tertiary health system. J Am Heart Assoc 2014; 3: e001152. doi:10.1161/JAHA 114.001152.

20. Obi AT, Pannucci C, Nackashi A, et al. Validation of the Caprini Venous Thromboembolism Risk Assessment Model in Critically Ill Surgical Patients. JAMA Surgery 2015; 150: 941-948.

21. Green MT, Spyropoulos AC, Chopra V, et al. Validation of risk assessment models of venous thromboembolism in hospitalised medical patients. Am J Med 2016; 129: doi: 10.1016/j.amjmed.2016.03.031.

22. Cohen AT, Spiro TE, Spyropoulos AC, et al. D-dimer as a predictor of venous thromboembolism in acutely ill hospitalised patients: a subanalysis of the randomised controlled MAGELLAN trial. J Thromb Haemost 2014; 12: 479-487.

23. Department of Health (2010) Venous Thromboembolism (VTE) Risk Assessment. Available at: https://h.gov.uk/en/Publicationsandstatistics/ PublicationsPolicyAndGuidance/DH_088215.

24. Lester W, Freemantle N, Begaj I, et al. Fatal venous thromboembolism associated with hospital admission: a cohort study to assess the impact of a national risk assessment target. Heart 2013; 99 : 1734-1739.

25. Catterick D, Hunt BJ. Impact of the national venous thromboembolism risk assessment tool in secondary care in England: retrospective population-based database study. Blood Coagul Fibrinolysis 2014; 25: 571-576.

26. Cassidy MR, Rosenkranz P, McAneny D. Reducing postoperative venous thromboembolism complications with a standardised risk-stratified prophylaxis protocol and mobilisation program. J Am Coll Surg 2014; 218: 1095-1104.

27. Cohen AT, Harrington, RA, Goldhaber, SZ, et al., for the APEX Investigators. Extended thromboprophylaxis with betrixaban in acutely ill medical patients. N Engl J Med 2016; 375: 534-544.

28. Raskob G, Spyropoulos AC, Zrubeck J, et al. The MARINER trial of rivaroxaban after hospital discharge for medical patients at high risk of VTE. Design, rationale, and clinical implications. Thromb Haemost 2016; 115: 1240-1248.

29. Grosse SD, Nelson RE, Nyarko KA, et al. The economic burden of incident venous thromboembolism in the United States: a review of estimated attributable healthcare costs. Thrombosis Res 2016; 137: 3-10. 